\title{
Integrated Mathematical Model of Pulverised Coal Combustion in a Blast Furnace
}

\author{
Kanji TAKEDA and F. C. LOCKWOOD')
}

Research Laboratories, Kawasaki Steel Corporation, Kawasaki-cho, Chuo-ku, Chiba, Chiba-ken, 260 Japan. 1) Imperial College of Science, Technology and Medicine, Exhibition Road, London, SW7 2BX, UK.

(Received on June 19, 1996; accepted in final form on January 14, 1997)

\begin{abstract}
The shortage of coke production due to the closure of coke ovens has led in Japan and other industrialised countries to increasing the injection of auxiliary fuels, e.g. pulverised coal (PC) into blast furnace tuyeres. The $\mathrm{PC}$ injection at high rates of more than $200 \mathrm{~kg} / \mathrm{t}$ requires high burnout within the raceway zone. In order to analyse flow and combustion in the raceway and to assist improvement of burner design, a two-dimensional mathematical model of PC combustion has been developed with simulating both the blowpipe and raceway.

Effects of a packed bed on the turbulent features of gas and particulate flow were introduced to the model along with all other pertinent phenomena such as heterogeneous reactions of coke and char particles. Validation work against measurements in two industrial blast furnaces indicated that the model has worked satisfactorily for simulation with and without PC injection.

Various measures for burnout improvements were explored under an injection rate of $200 \mathrm{~kg} / \mathrm{tHM}$. Notable improvements were observed by oxygen enrichment to the secondary air and enlargement of the outer diameter of the injection burner.
\end{abstract}

KEY WORDS: ironmaking; pulverised coal injection; mathematical model; raceway; turbulence; combustion.

\section{Introduction}

The most important change in blast furnace technology over the past decade has been the introduction and subsequent increase in the levels of coal injection. In late 1980 s, the problems of ageing coke ovens and relevant shortage of coke supply in the near future became apparent. Most coke ovens built during the rapid growth of the Japanese economy in 1960s are predicted to be closed at the beginning of the next century with the expected life span of 35 years. The first Japanese pulverised coal (PC) injection plant commenced its operation in 1981 at No. 1 blast furnace at Oita Works, Nippon Steel Corporation. ${ }^{1)}$ Several operational trials for higher PC injection rates of more than $200 \mathrm{~kg} \mathrm{tHM}^{-1}$ are found in references. ${ }^{2-4)}$ The annual PC rate of $201 \mathrm{~kg} \mathrm{tHM}^{-1}$ was recorded at No. 1 blast furnace at Kakogawa Works while monthly injection rate of 207 was achieved in Aug. 1994. ${ }^{5)}$ The highest monthly injection rate was $218 \mathrm{~kg} \mathrm{tHM}^{-1}$ at No. 4 blast furnace at Fukuyama Works.

The combustion process in the raceway of an industrial blast furnace is clearly complex and detailed measurements are extremely difficult to undertake due to the high temperature, high pressure, presence of molten materials, lack of accessibility and the inevitable reduction in production. Another route forward is the development of a mathematical model of PC injection.
Many attempts of mathematical modelling of combustion in the raceway have been reported in Europe and Japan. ${ }^{6-11)}$ Although there are many difficulties involved in precise modelling of the raceway phenomena, models are used as guidelines to improve the $\mathrm{PC}$ injection facilities and operations. Features common to many existing one-dimensional models for the raceway zone are that the raceway is assumed as a loosely packed bed with high porosity through which the hot blast flows as a cylindrical, non-spreading jet. ${ }^{6-9)}$ Two-dimensional models were developed by Hatano et $a l^{10)}$ and Nogami et al. ${ }^{11)}$ Their model approximated a coke packed bed with a quasi-fluid. Motion of the coke particles was calculated from the momentum transport equations similar to those of the gas phase.

None of the previous models consider the turbulent features in the raceway and surrounding packed beds. Turbulent properties are required for the predictions of radial mixing of gas species, gaseous combustion kinetics of volatiles and dispersion of the PC stream. Objectives of this study were to develop an integrated twodimensional mathematical model of PC combustion simulating both the blowpipe and the raceway zone in a blast furnace. The model includes a modified turbulence model $\left(k-l_{\mathrm{m}}\right.$ model) and a stochastic calculation of particle trajectories in a packed bed developed in previous studies $^{12,13)}$ as well as additional heterogeneous reactions of coke particles. Measured gas composition in the 
blowpipe and raceway $^{8,14)}$ was used for validation purposes of the model. Industrial implications of the model will be demonstrated through case studies on the effects of burner design on the overall burnout.

\section{Development of Two-dimensional Mathematical Mod- el of PC in the Blowpipe and Raceway}

\subsection{Features of the Mathematical Model}

A two-dimensional model of the PC combustion in the blowpipe and raceway in a blast furnace takes into account many phenomena such as heterogeneous reactions of coke particles besides the basic transport equations and reactions of coal particles in the general computer code for PC combustion. Features of the model are summarised in Table 1. As details of the original code are available elsewhere ${ }^{15}$ ) only the additional functions in the present code will be explained in this section.

In the blowpipe region, major modifications are related to the particle trajectory calculations. The stochastic method is implemented to consider the effects of the fluctuation of gas velocities on particle dispersion. This allows one to evaluate precisely the influences of burner modifications on the particle dispersion in the blowpipe. The same rate constants as those established by authors ${ }^{16)}$ are employed for calculating devolatilisation rates, and the volatile and char combustion rates.

In the raceway region, the $k-l_{\mathrm{m}}$ turbulence model proposed by authors ${ }^{12}$ is included for the gas flow calculation. Resultant turbulent kinetic energy is used to predict particle dispersion in a packed bed. Modified momentum equations, by adding the pressure drop of the Ergun's equation, are discretised on a staggered grid system by the hybrid difference scheme. The TDMA method and the SIMPLE or PISO algorithm are used for solving the matrix and the pressure correction equation respectively. ${ }^{15}$ )

Table 1. Phenomena considered in the total model of the PC combustion in the blowpipe and raceway.

\begin{tabular}{|c|c|}
\hline Blowpipe region & Coke packed bed region (raceway) \\
\hline $\begin{array}{l}\text { 1) Particle trajectory calculation with } \\
\text { stochastic model } \\
\text { 2) Devolatilisation and char combustion of } \\
\text { coal particle } \\
\text { 3) Eddy dissipation model for volatiles } \\
\text { combustion }\end{array}$ & $\begin{array}{l}\text { 1) Fluid flow calculation } \\
\text { - Momentum equation with Ergun's } \\
\text { equation } \\
\text { • } \mathrm{k}-\mathrm{I}_{\mathrm{m}} \text { turbulence model } \\
\text { 2) Mass and heat transport equations } \\
\text { - Transport equations of oxygen, } \\
\text { carbon, hydrogen and volatiles mass } \\
\text { fraction } \\
\text { 3) Particle trajectory calculation with the } \\
\text { interaction of particles with a packed bed } \\
\text { 4) Heterogeneous reaction } \\
\text {-Coke combustion and solution loss } \\
\text { reaction } \\
\text {-Char combustion and solution loss } \\
\text { reaction } \\
\text { 5) Equilibrium state amongst the gas } \\
\text { species, }\left(\mathrm{O}_{2}, \mathrm{CO}, \mathrm{CO}, \mathrm{H} 2, \mathrm{H}_{2} \mathrm{O}\right)\end{array}$ \\
\hline
\end{tabular}

In addition to three momentum equations, seven transport equations are solved for scalar variables; turbulence kinetic energy, eddy dissipation rate, mass fractions of carbon, hydrogen, oxygen, volatiles, enthalpy of gas. Mass fractions of carbon, oxygen and hydrogen are used as independent scalar variables because these values are conserved with respect to the gaseous reactions: $\mathrm{CO}+1 / 2 \mathrm{O}_{2}=\mathrm{CO}_{2}$ and $\mathrm{H}_{2}+1 / 2 \mathrm{O}_{2}=\mathrm{H}_{2} \mathrm{O}$.

Additional heterogeneous reactions are taken into account in the model, such as the coke combustion and reactions of carbon with carbon dioxide and water. Details of the reaction scheme are given in Fig. 1. The coal particles are heated and release volatiles to form residual char. Volatiles composed of known contents of carbon, hydrogen and oxygen react with oxygen to produce carbon monoxide and water with the reaction rates based on the eddy dissipation model. ${ }^{17)}$

Two heterogeneous reactions of char and coke particles are introduced in the model. According to the examination of reaction scheme by Jamaluddin, ${ }^{8)}$ the carbon in the char particles reacts with oxygen to form carbon monoxide while it reacts with carbon dioxide simultaneously. Coke particles with a temperature of $80 \%$ of gas temperatures, burn to form carbon dioxide. The combustion rate of coke particles is calculated with the chemical reaction rate and the gas diffusion rate in the gas boundary layer at a predetermined slip velocity. The slip velocity between gas and coke particle is assigned with a product of the gas velocity and slip velocity ratio. The primary product of the coke combustion is carbon dioxide due to the slower gas diffusion rate through the boundary layer than the gaseous reaction rate. The secondary reactions with carbon dioxide and water take place at the same time. Rate constants of heterogeneous reactions are selected from the basic measurements available in the literature. ${ }^{8)}$

The resultant mass and heat transfer from the solid and volatiles phase to the gas phase is added to the source term in the transport equations of mass, hydrogen, oxygen, carbon and enthalpy. An equilibrium state amongst the major gas species, $\mathrm{O}_{2}, \mathrm{CO}, \mathrm{CO}_{2}, \mathrm{H}_{2}$ and $\mathrm{H}_{2} \mathrm{O}$ is assumed to obtain gas compositions at known

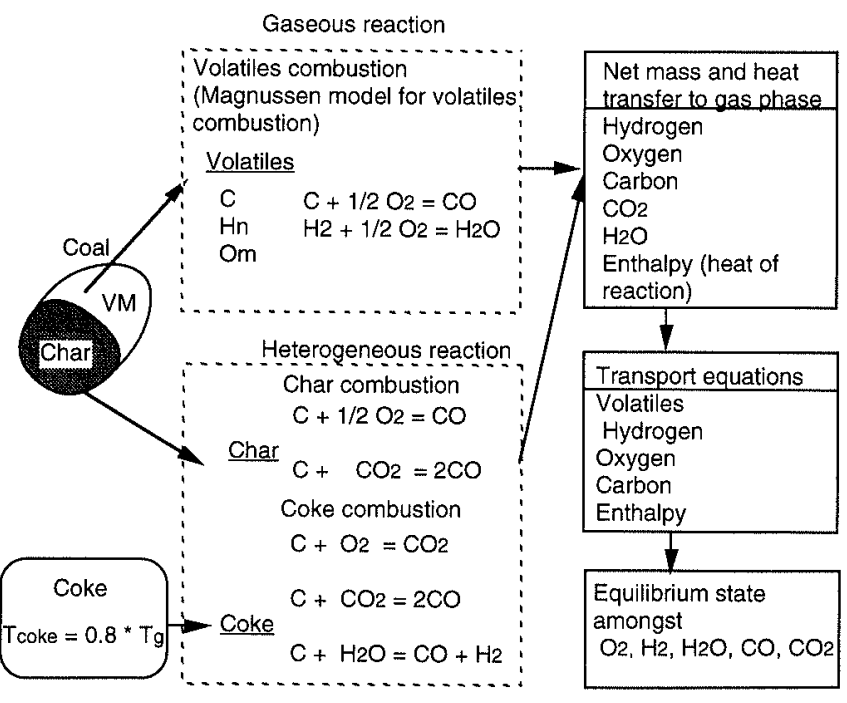

Fig. 1. Reaction scheme of pulverised coal and coke. 
temperatures. The separate phase of volatiles allows to incorporate the eddy dissipation model used in the original code as a gaseous combustion model. A standard grid of $37 \times 51$ is used for the simulation in the following section. The CPU time for one converged result is about $300 \mathrm{~min}$ on a DEC 5000 work station.

\subsection{Physical Conditions of the Raceway}

Besides the mathematical modelling of gas and PC flow, geometry and void fraction of the raceway should be properly considered in the total model. Coke particles falling from a narrow area in front of the tuyere were accelerated by the jet from the tuyere as given by Elliot et al. ${ }^{18)}$ in Fig. 2. Direct measurements of void fraction in the raceway were recently carried out by Nozawa $e t$ al. ${ }^{19)}$ The raceway consists of two regions, the jet core region with relatively high and constant void fraction and the transition region with the linear decrease in voidage to the raceway boundary.

In summary, we assume that the raceway consists of two axi-symmetrical regions; the jet zone and the transition zone between the jet zone and surrounding

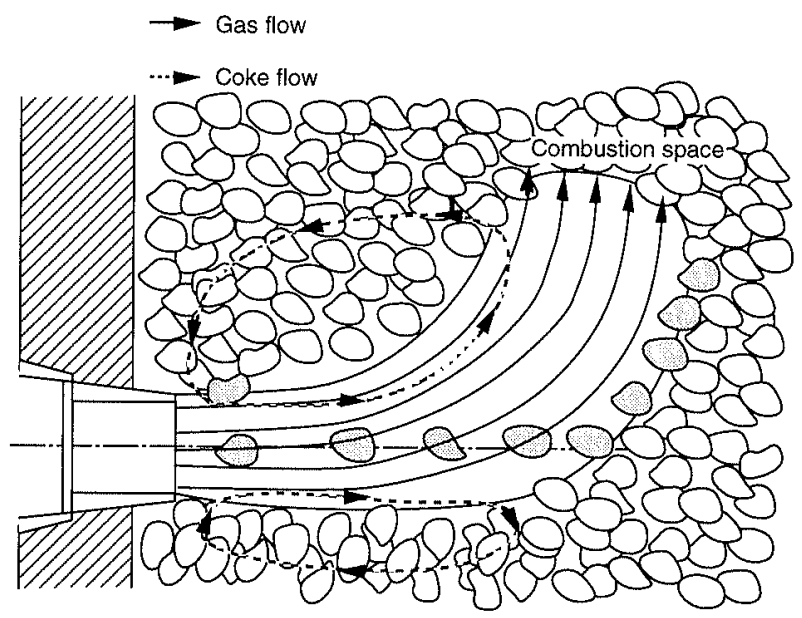

Fig. 2. Representation of the movement of coke particles through the raceway based on the observations with an endoscope by Elliott et al. ${ }^{17}$

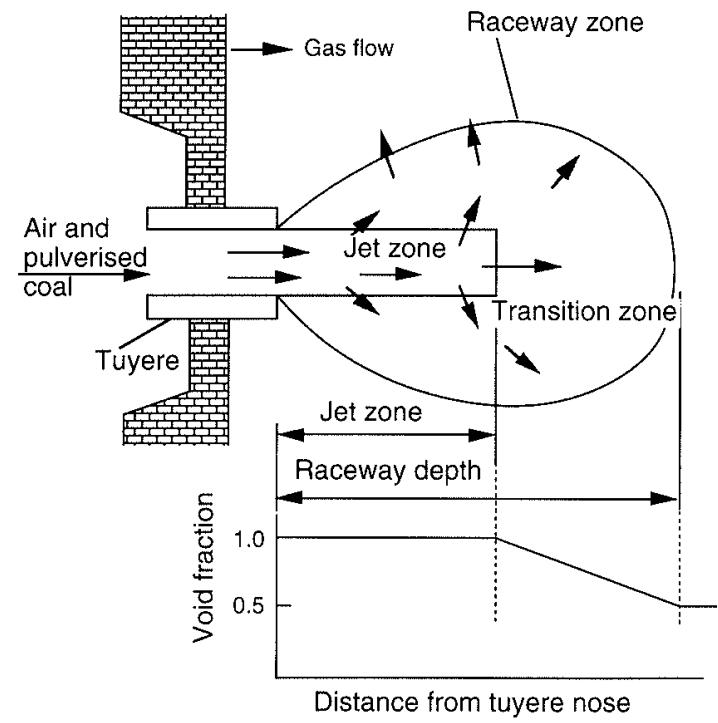

Fig. 3. Schematic representation of the raceway structure used in the simulation. packed bed for a computational model. The jet zone with the void fraction of 1.0 has the same diameter of the tuyere and the depth is about one half of the raceway depth as shown in Fig. 3. The transition zone is the loosely packed region where the void fraction may be realistically assumed to change linearly from 1.0 to the packed bed void fraction of 0.5 . The shape of the transition zone was estimated with the experimental correlation by Nakamura et al. ${ }^{20)}$

\section{Model Validation}

Two-dimensional models are able to predict field variables with fewer model parameters than required by the one-dimensional models of Jamaluddin ${ }^{8)}$ and $\mathrm{He}$ et al. ${ }^{9)}$ However, the mathematical model of the coal and coke combustion in the raceway requires additional information on the raceway structure. Validation work of the model is conducted with two steps:

1) Coke combustion and gas flow in the raceway without

PC injection at No. 1 blast furnace at Chiba Works, Kawasaki Steel Corporation. ${ }^{14)}$

2) Coke and PC combustion in the raceway with PC injection at No. 4 blast furnace at Newcastle Works, BHP. ${ }^{81}$

\subsection{Predictions of the Coke Combustion and Gas Flow in the Raceway without PC Injection}

Simulations of the combustion process in the raceway without PC injection are carried out under the operating conditions of the No. 1 blast furnace at Chiba Works as listed in Table 2. Details of operating conditions and gas compositions in the raceway were measured by Inatani et $a .^{141}$

Axial profiles of $\mathrm{CO}_{2}, \mathrm{CO}$ and $\mathrm{O}_{2}$ at the centre of the raceway in Figs. 4 and 5 indicate that the prediction is in good agreement with the measured data. The profile of oxygen depreciation, the position of the maximum $\mathrm{CO}_{2}$ and the sharp increase in $\mathrm{CO}$ are all simulated very well. Small discrepancies in the early stages of the coke combustion may be caused by minor misalignment of the probe from the tuyere centre.

\subsection{Predictions with PC Injection at Newcastle No. 4 Blast Furnace}

The model was applied to the predictions of the PC combustion phenomena in the Newcastle No. 4 blast

Table 2. Operating conditions of No. 1 blast furnace at Chiba Works, Kawasaki Steel Corp.

\begin{tabular}{|l|c|}
\hline Inner volume & $966 \mathrm{~m}^{3}$ \\
\hline Productivity & 1600 ton hot metal day-1 \\
\hline Diameter of tuyere & $0.16 \mathrm{~m}$ \\
\hline Raceway depth & $1.5 \mathrm{~m}$ \\
\hline Blast temperature & $970-1000^{\circ} \mathrm{C}$ \\
\hline Blast pressure & $2.08-2.2 \cdot 10^{5} \mathrm{~Pa}(\mathrm{abs})$ \\
\hline Oxygen concentration in blast & $0.233 \mathrm{~kg}-02 \mathrm{~kg}^{-b l a s t}{ }^{-1}$ \\
\hline Moisture concentration in blast & $18-24 \mathrm{~g} \mathrm{Nm}^{-3}$ \\
\hline Flow rate of blast & $24.7 \mathrm{Nm}^{3} \mathrm{~s}^{-1}$ \\
\hline
\end{tabular}




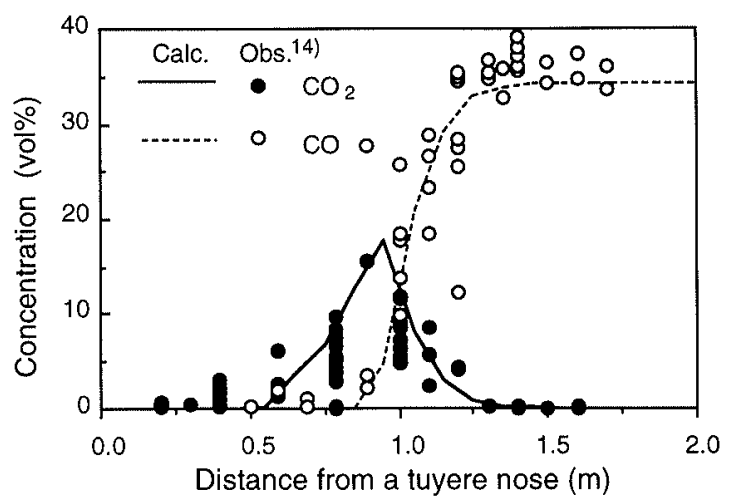

Fig. 4. Axial profiles of gas compositions at the centre of the raceway: measured and predicted.

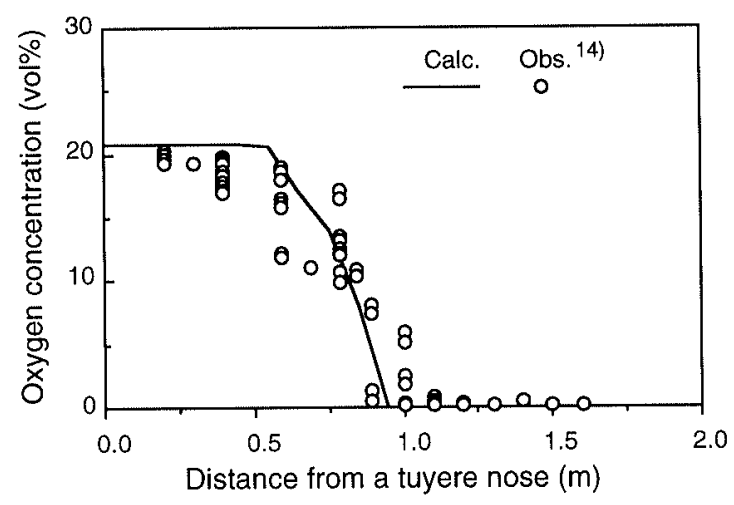

Fig. 5. An axial profile of oxygen concentrations at the centre of the raceway: measured and predicted.

Table 3. Operation data of No. 4 blast furnace at Newcastle Works.

\begin{tabular}{|l|c|}
\hline Working volume & $1268 \mathrm{~m}^{3}$ \\
\hline Productivity & $2400 \mathrm{tHM} \mathrm{day}^{-1}$ \\
\hline Diameter of tuyere & $0.13 \mathrm{~m}$ \\
\hline Length of tuyere & $0.38 \mathrm{~m}$ \\
\hline Raceway depth & $0.8-1.0 \mathrm{~m}$ \\
\hline Blast temperature & $1283^{\circ} \mathrm{C}$ \\
\hline Blast pressure & $3.5 \cdot 10^{5} \mathrm{~Pa}$ (abs) \\
\hline Oxygen concentration in blast & $0.276 \mathrm{~kg}^{-} \mathrm{O}_{2} \mathrm{~kg}_{-}$-blast \\
\hline Moisture concentration in blast & $45 \mathrm{~g} \mathrm{Nm}^{-3}$ \\
\hline Pulverised coal flow rate & $50 \mathrm{kgtHM}^{-1}$ \\
\hline Flow rate of blast & $2.00 \mathrm{Nm}^{3} \mathrm{~s}^{-1}$ tuyere-1 \\
\hline
\end{tabular}

furnace in Australia. This furnace was selected because measured data in the blowpipe and raceway for operation with and without PC injection are available in the reference. ${ }^{8)}$ The operating conditions at Newcastle No. 4 blast furnace are given in Table 3 . The jet zone depth and void fraction in the raceway were assumed in a similar manner to No. 1 blast furnace at Chiba Works based on the measured raceway depth as shown in Fig. 6.

The simulation with PC injection was carried out for high volatile coal $(\mathrm{VM}=38.7 \%)$. Ultimate and proximate analyses are shown in Table 4. Four size groups of particles were injected from four starting locations within the injection pipe as listed in Table 4. Since de-

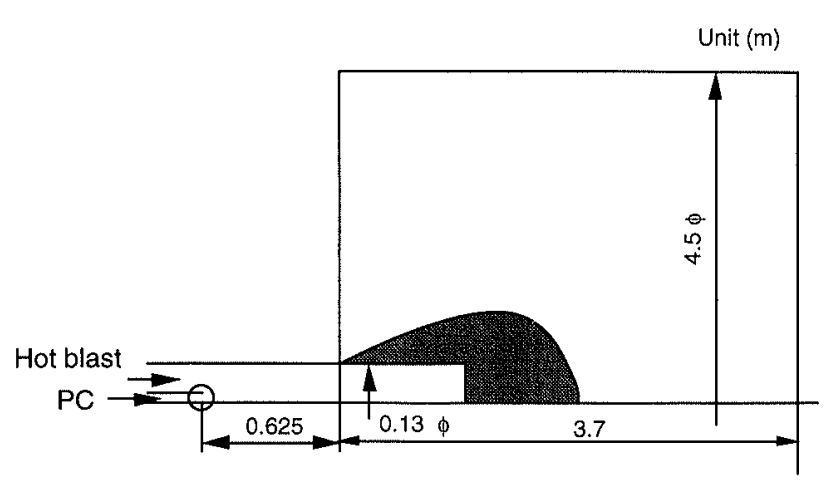

Fig. 6. Simulation conditions of the coke and PC combustion at the Newcastle No.4 blast furnace.

Table 4. Coal injection at Newcastle No.4 blast furnace.

\begin{tabular}{|c|c|c|c|}
\hline \multicolumn{2}{|c|}{$\begin{array}{l}\text { Proximate analysis } \\
\text { (db\%) }\end{array}$} & \multicolumn{2}{|c|}{$\begin{array}{l}\text { Ultimate analysis } \\
(\mathrm{db} \%)\end{array}$} \\
\hline $\begin{array}{l}\text { Moisture } \\
\text { Ash } \\
\text { Volatile content } \\
\text { Fixed carbon }\end{array}$ & $\begin{array}{l}3.75 \\
7.10 \\
38.70 \\
50.45\end{array}$ & $\begin{array}{l}\mathrm{C} \\
\mathrm{H} \\
\mathrm{O} \\
\mathrm{N} \\
\mathrm{S}\end{array}$ & $\begin{array}{l}74.3 \\
4.82 \\
8.01 \\
1.60 \\
0.41\end{array}$ \\
\hline Size group, i & \multicolumn{2}{|c|}{$\begin{array}{l}\text { Mean diameter } \\
(\mu \mathrm{m})\end{array}$} & $\begin{array}{l}\text { Fraction } \\
(-)\end{array}$ \\
\hline $\begin{array}{l}1 \\
2 \\
3 \\
4\end{array}$ & \multicolumn{2}{|c|}{$\begin{array}{l}10.0 \\
24.5 \\
42.4 \\
80.0\end{array}$} & $\begin{array}{l}0.10 \\
0.15 \\
0.66 \\
0.09\end{array}$ \\
\hline \multicolumn{2}{|c|}{ Starting location, $\mathrm{j}$} & \multicolumn{2}{|c|}{ Radial position (m) } \\
\hline $\begin{array}{l}1 \\
2 \\
3 \\
4\end{array}$ & & $\begin{array}{l}0.0012 \\
0.0037 \\
0.0063 \\
0.0088\end{array}$ & \\
\hline
\end{tabular}

tailed particle size distributions measured during the experiments were not found in the paper, ${ }^{8)}$ a mean size and its fraction of each particle group were estimated based on the typical distribution of PC and the mean size in the paper.

Predictions of the $\mathrm{PC}$ combustion with a high volatile coal have distinct features as found in contours of field variables in Figs. 7-9. A relatively small axial velocity region appears in the downstream region of the blowpipe due to the low velocity of the primary air and coal. The gas temperature in the central region increases rapidly by mixing with the hot secondary air. Although the devolatilisation starts in the blowpipe, the volatiles combustion is not significant within the blowpipe as indicated by the fact that the gas temperatures at the exit of the blowpipe reach $1473 \mathrm{~K}$, slightly above the secondary air temperature. Further downstream, the highest temperature region appears at the axis as a result of the intense coal combustion.

The number of stochastic trials for the particle trajectory calculation is 25 for each size group and location, with an under relaxation factor of 0.1. Several trajectories in each size and location are plotted in Fig. 10. The particles change their direction soon after injection. A large shear stress caused by the velocity differences of the primary and secondary air generates an intense mixing region with a high turbulent kinetic energy and large turbulent diffusion coefficient. Injected 


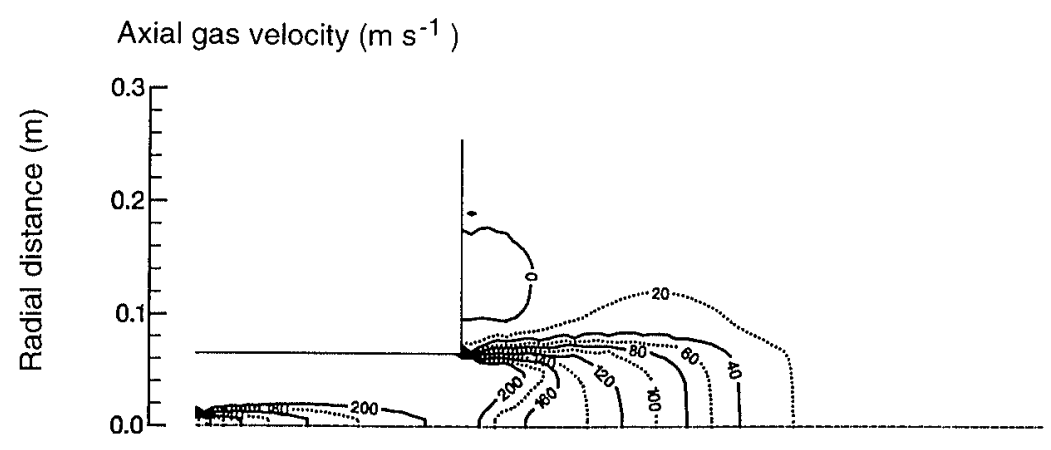

Radial gas velocity $\left(\mathrm{m} \mathrm{s}^{-1}\right)$

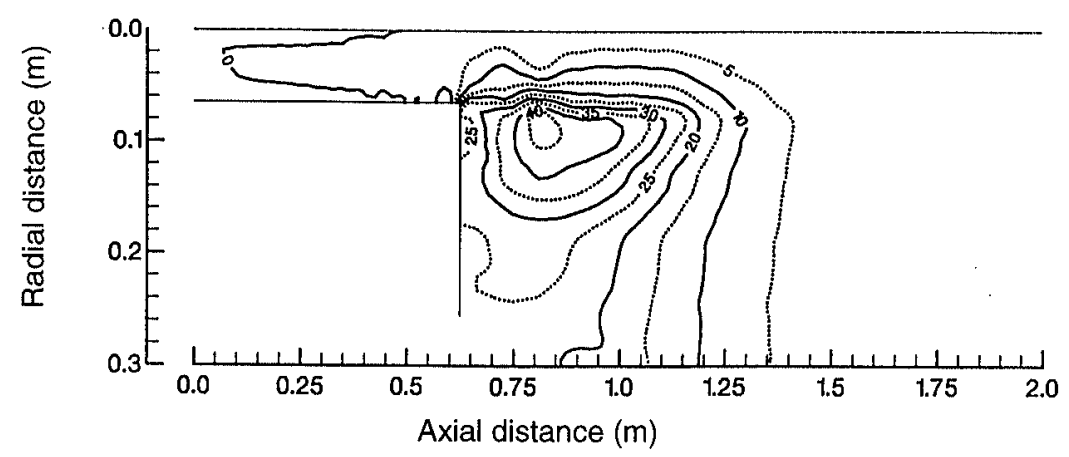

Gas temperature $\left({ }^{\circ} \mathrm{C}\right)$

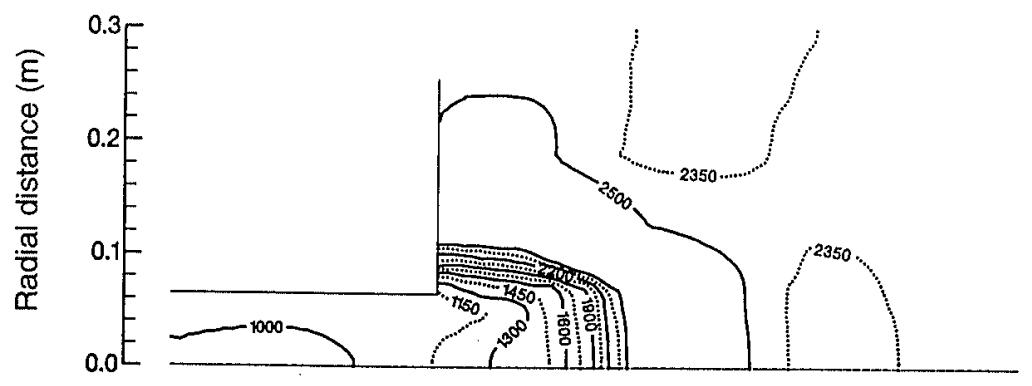

Oxygen concentration (\%)

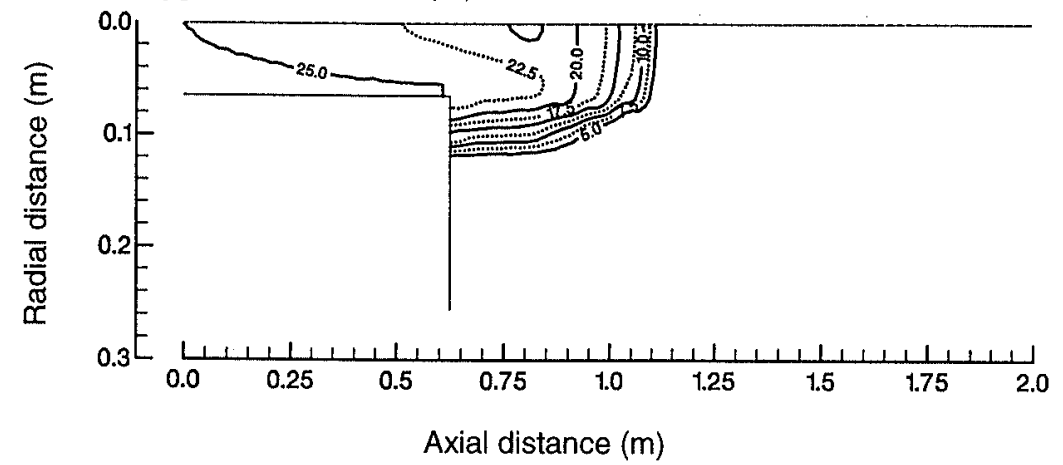

Fig. 7.

Predictions of velocity profiles for the injection of high volatile coal at an injection rate of $50 \mathrm{~kg} \mathrm{tHM}^{-1}$.

\section{Fig. 8.}

Predictions of the combustion processes in the raceway for the injection of high volatile coal at an injection rate of $50 \mathrm{~kg}$ $\mathrm{tHM}^{-1}$. particles respond to the gas turbulence immediately and are dispersed rapidly at the downstream of the injection pipe. This initial dispersion reaches roughly the radial position of the outer surface of the injection pipe. Further particle dispersion occurs continuously in the blow pipe. After entering the raceway, most of the particles change their direction outwards at the end of the jet zone and in the transition zone. The rapid spreading is attributed to the outward gas flow and large turbulent kinetic energy generated by the interaction of the injected gas and the packed bed.
Contour lines of spatial particle mass densities are presented in Fig. 11. The densities are obtained by adding the residence time in each control volume during stochastic trials. Rapid dispersion is observed at the exit of the injection pipe and steady spreading continues in the blowpipe. The sudden expansion of the contour line at axial position, $x=0.85 \mathrm{~m}$ suggests strong mixing in the coke packed bed.

Axial profiles of gas compositions are plotted for predictions and measurements in Fig. 12. Predictions of oxygen, carbon monoxide and carbon dioxide exhibit 
$\mathrm{CO}(\%)$

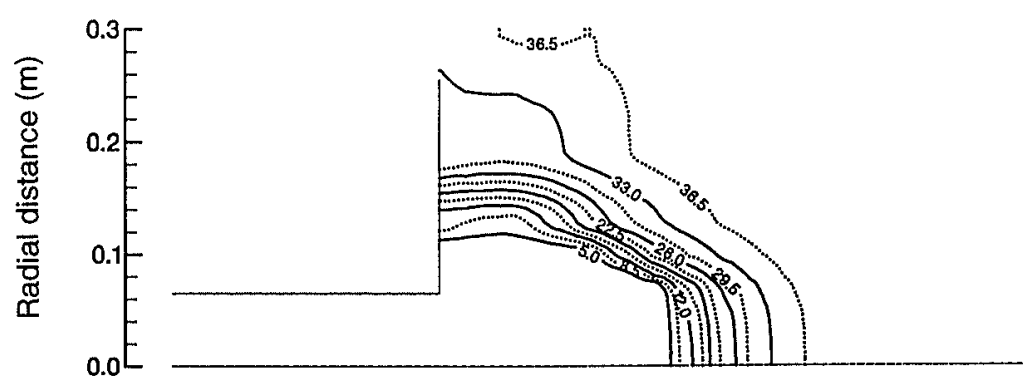

$\mathrm{CO} 2(\%)$

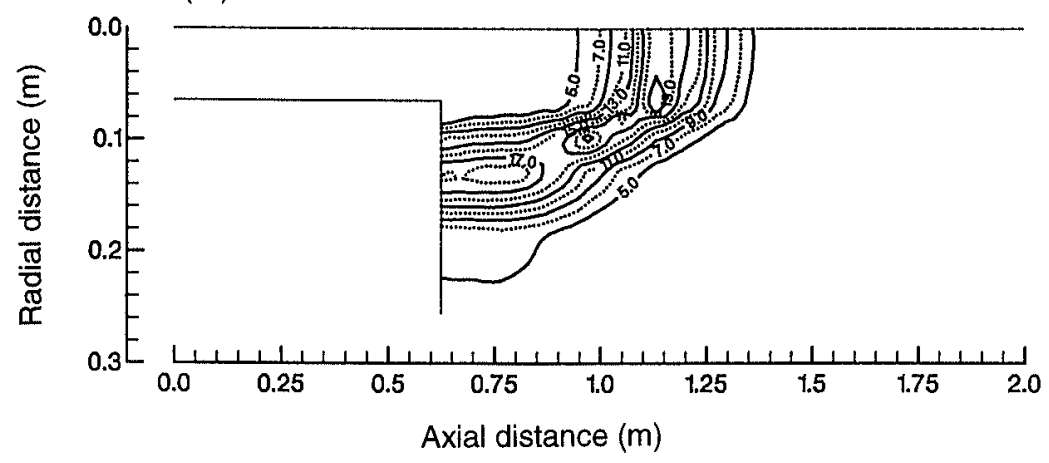

Fig. 9.

Predictions of $\mathrm{CO}$ and $\mathrm{CO}_{2}$ in the raceway for the injection of high volatile coal at an injection rate of $50 \mathrm{~kg} \mathrm{tHM}^{-1}$.

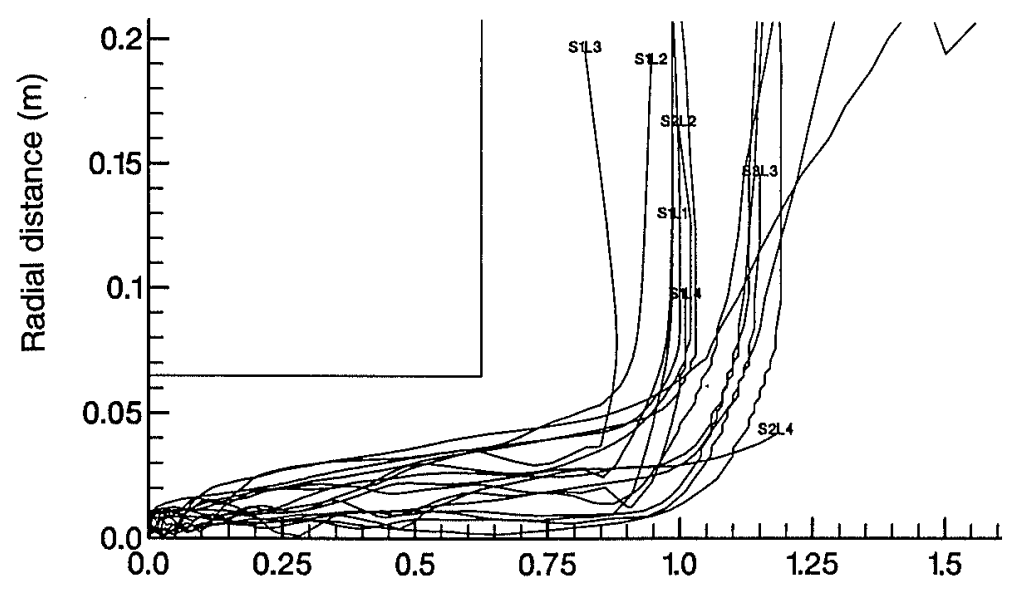

Fig. 10.

Typical particle trajectories predicted by the stochastic model for the injection of high volatile coal at an injection rate of $50 \mathrm{~kg} \mathrm{tHM}^{-1}$. Symbols, $\mathrm{SiLj}$, denote the size group $\mathrm{i}$ and starting location

Axial distance $(\mathrm{m})$ $\mathrm{j}$ for the coal particle trajectories.

Particle density $\left(\mathrm{kg} \mathrm{m}^{-3}\right)$

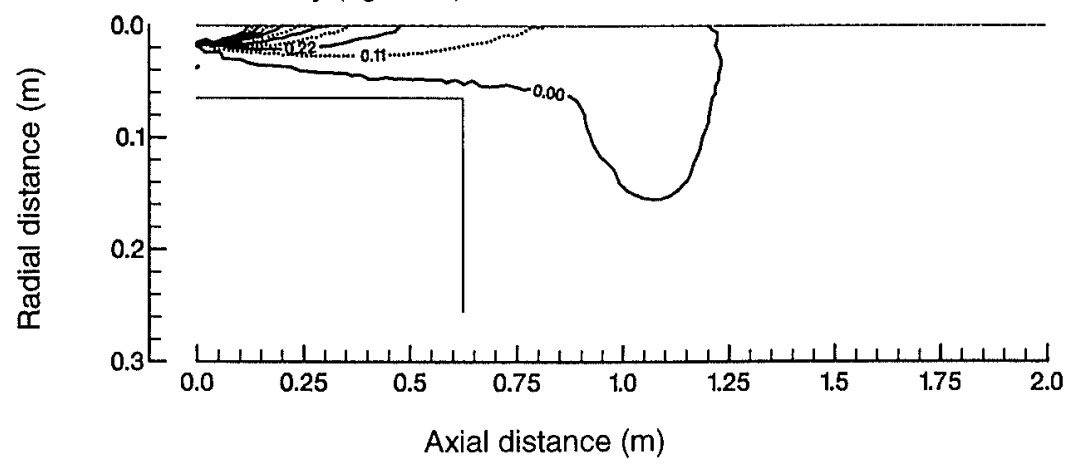

Fig. 11.

Particle dispersion predicted by the stochastic model for the injection of high volatile coal at an injection rate of $50 \mathrm{~kg}$ $\mathrm{tHM}^{-1}$.

good agreement with measured data. Early depreciation of the oxygen concentration indicates that the combustion of the volatiles takes place in the blowpipe and raceway. Oxygen concentrations slightly recover at $x=0.25 \mathrm{~m}$ due to the strong radial mixing of the gas phase in the raceway zone.
4. Discussions on the Burnout Improvements in the Raceway

Future injection rates of the $\mathrm{PC}$ in a blast furnace are expected to be more than $200 \mathrm{~kg} \mathrm{tHM}^{-1}$ that is four times higher than that at Newcastle No. 4 blast furnace. 


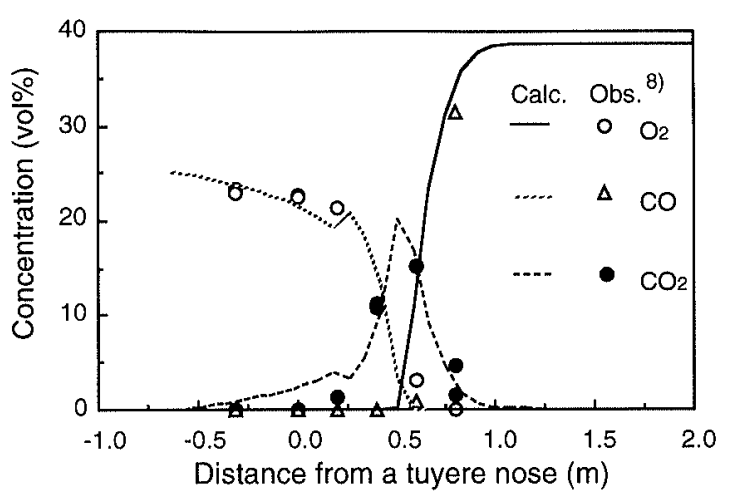

Fig. 12. Predictions of axial profiles of gas compositions in the raceway for the injection of high volatile coal, $\mathrm{VM}=38.7 \%$.

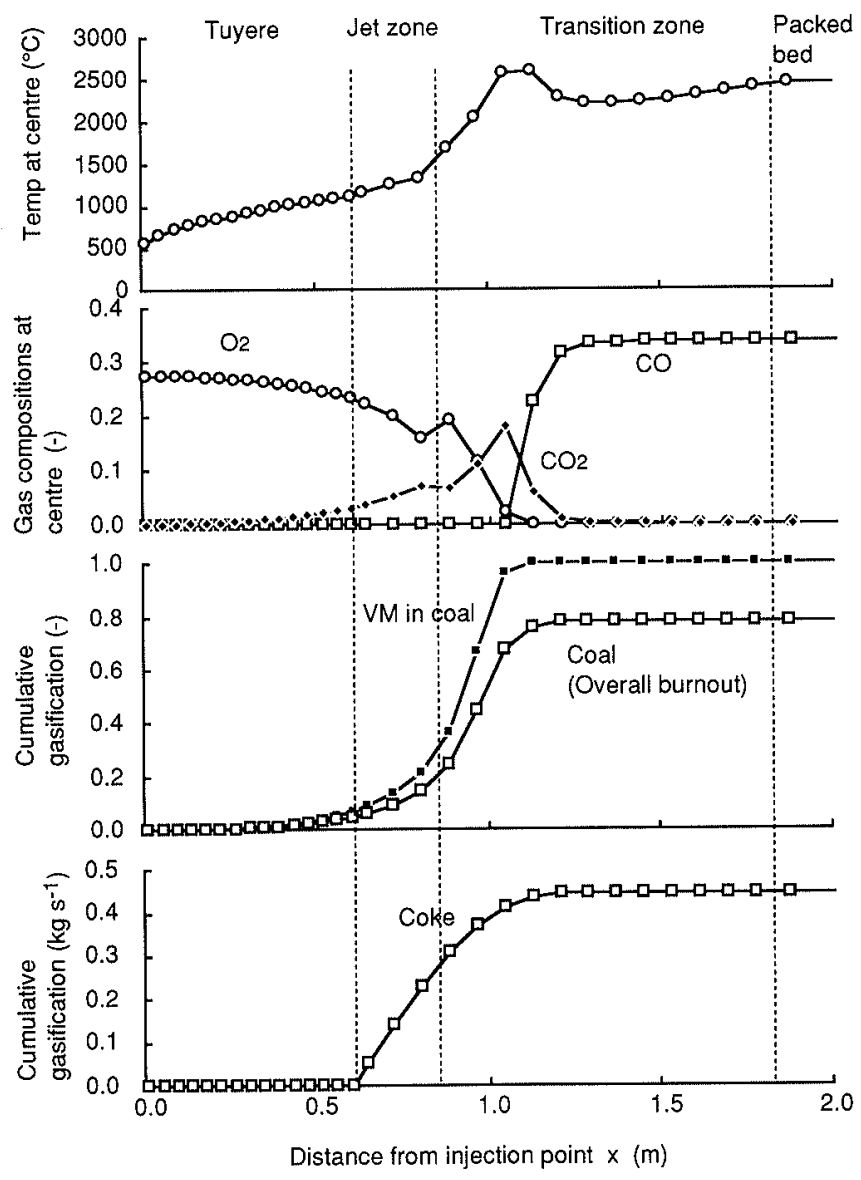

Fig. 13. Combustion of pulverised coal in the tuyere and raceway at an injection rate of $200 \mathrm{kgt} \mathrm{HM}^{-1}$.

In order to obtain a more distinct view on the combustion behaviour at an injection rate of $200 \mathrm{~kg} \mathrm{tHM}^{-1}$, injection rates in simulations were increased $200 \mathrm{~kg} \mathrm{tHM}^{-1}$. Then, with the injection rate fixed at $200 \mathrm{~kg} \mathrm{tHM}^{-1}$, various operational and design modifications were predicted to examine their effects on the burnout.

\subsection{Combustion of Pulverised Coal at an Injection Rate of $200 \mathrm{~kg} \mathrm{tHM} \mathbf{~}^{-1}$}

The combustion process in the blowpipe and raceway were found in Fig. 13 at an injection rate of $200 \mathrm{~kg}$ $\mathrm{tHM}^{-1}$. A gradual increase in gas temperature in the tuyere and jet zone indicates slow mixing of hot blast and PC and resultant delayed combustion of released volatiles. As entering the transition zone, the pulverised coal releases volatiles and the gasification of coal rapidly proceeds. Slight recovery of oxygen concentration at the transition zone is caused by the intense radial mixing of gas and PC. After the complete depreciation of oxygen, the solution loss reaction, $\mathrm{C}+\mathrm{CO}_{2}=2 \mathrm{CO}$, dominates the gasification of coal. A small temperature increase after the completion of the solution loss reaction is due to the radiation heat transfer from the high temperature zone. Net burnout which is defined as a ratio of burnt volatiles and char to the injected combustible materials are obtained at the outlet of the calculation domain.

As the gasification of coke particles takes places at the upper transition zone, 'roof of the raceway', as well, cumulated gasification of coke starts increasing at the axial position $x=0.6 \mathrm{~m}$. Hot blast which escapes from the roof of the raceway does not have a chance to react with the injected pulverised coal. Therefore, improvements in the mixing rate of pulverised coal and oxygen in the tuyere and jet zone are the key for the higher burnout.

\subsection{Oxygen Supply Method}

Some of the previous work in laboratory scale and industrial blast furnaces have focused on the burnout changes with various conditions of PC injection. Campbell et al. ${ }^{21)}$ and Ohno et al. ${ }^{22)}$ have been particularly interested in the burnout improvement by optimising burner geometry and oxygen enrichment. Due to the limitations of existing one-dimensional models, few qualitative analyses have been reported on the effects of these essentially two-dimensional modifications. Effect of injection conditions on the burnout is discussed in this sub-section through several case studies for enriched oxygen supply method and burner geometry at an injection rate of $200 \mathrm{~kg} \mathrm{tHM}^{-1}$. Three oxygen supply methods for additional $2 \%$ oxygen enrichment were simulated at an injection rate of $200 \mathrm{~kg} \mathrm{tHM}^{-1}$.

In Case A, enriched oxygen was uniformly added to the secondary air. This represents a typical conventional practice in a blast furnace that the enriched oxygen is mixed with combustion air at a blower plant and heated up in a hot stove. Recently, Peters et l. $^{23)}$ have developed a coaxial burner for a high injection rate, where the PC stream is fed at centre and the enriched oxygen is added directly in the vicinity of the coal stream. Case B simulates the flow and combustion conditions of the coaxial burner. Campbell et al. ${ }^{21)}$ have developed the oxy-coal burner. Two burners are located at different axial positions, one for the enriched oxygen in the upstream and the other for the coal. The supplied oxygen was mixed with hot air and heated up before reaching the combustion zone in the blowpipe. These conditions are realised in Case $\mathrm{C}$ where oxygen was supplied to the surrounding region of the injection burner at the same temperature of hot air.

Differences in axial temperature profiles of three cases are relatively small as presented in Fig. 14. In Case B, a large amount of low temperature oxygen added to the primary line delays the heating and successive combustion processes. The highest net burnout was obtained in 


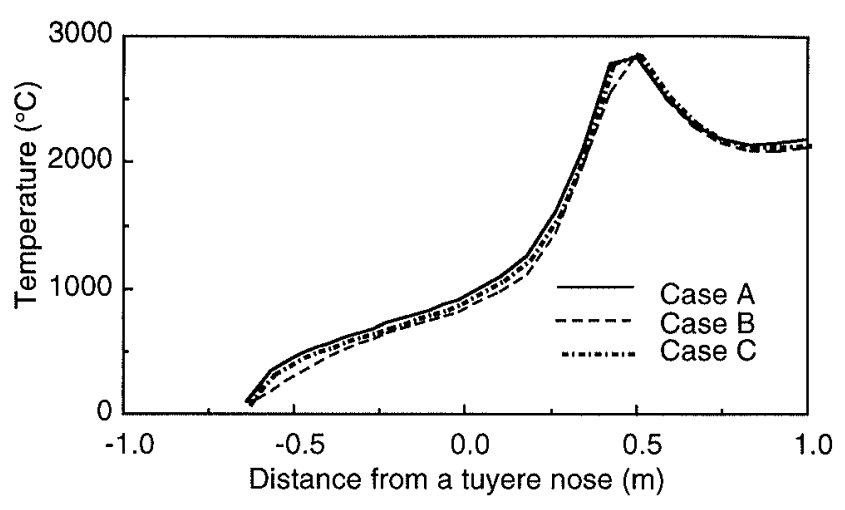

Fig. 14. Effect of the oxygen supply method on oxygen concentration.

Case A: Uniformly enriched to the hot blast

Case B : Enriched to the primary air.

Case $\mathrm{C}$ : Heated oxygen addition outside the primary air.

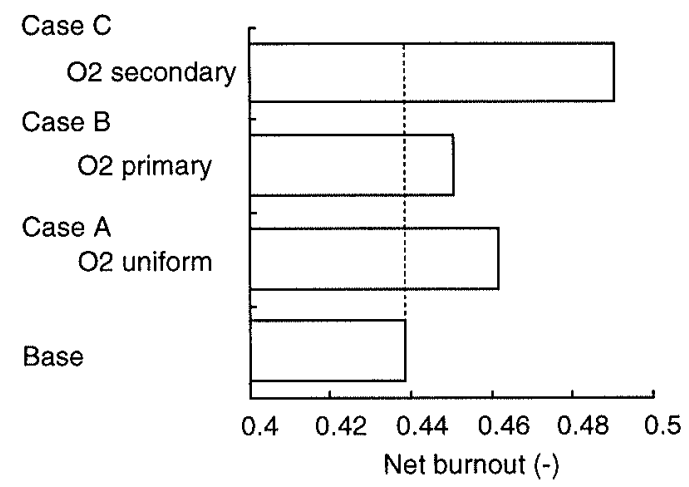

Fig. 15. Effect of the oxygen supply method on burnout.

Case $\mathrm{C}$ as shown in Fig. 15.

\subsection{Modifications of the Burner Design}

Four types of burners shown in Fig. 16 were simulated. Swirl motion was imposed to the primary air and coal flow in Case D. An outer diameter of the injection burner was enlarged from 0.020 to $0.040 \mathrm{~m}$ in order to enhance gas turbulence in the vicinity of the injection burner in Case E. Radial velocities were added to the initial gas and particle velocity at the exit of the injection burner in Case F.

The predictions of the net burnout are shown in Fig. 17. The net burnout for Case $\mathrm{D}$ and $\mathrm{F}$ are very close to the base condition. The highest net burnout was obtained for Case E, an increase in the outer diameter. Small changes amongst Base, Case $\mathrm{D}$ and $\mathrm{F}$ are explained by the fairly small momentum ratio of the primary air to the secondary air. Changes of the primary air flow such as swirl motion hardly generates significant influences on the flow and particle dispersion even in the near burner zone. However, an increase in the outer diameter of the injection pipe gives better mixing of the coal stream and gas through the intense turbulence downstream of the injection burner. The gas turbulence in the near burner zone is enhanced by increasing the outer diameter of the injection pipe as found in the contour lines of the particle mass density in Fig. 18.

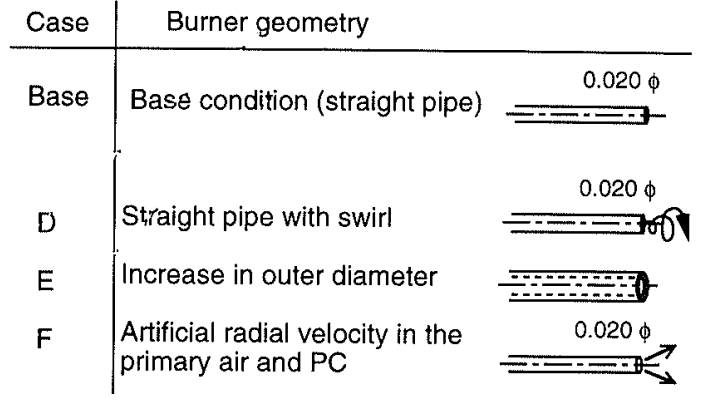

Fig. 16. Effect of burner geometry and injection conditions on the combustion behaviour of injected pulverised coal.
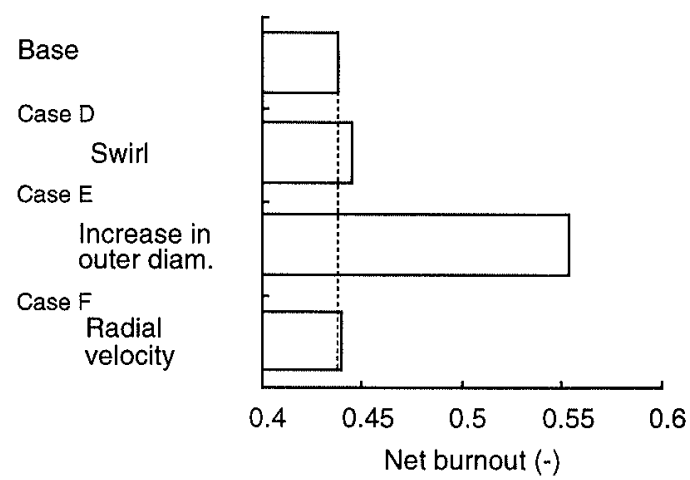

Fig. 17. Effect of burner geometry and injection conditions on the combustion behaviour of injected pulverised coal.
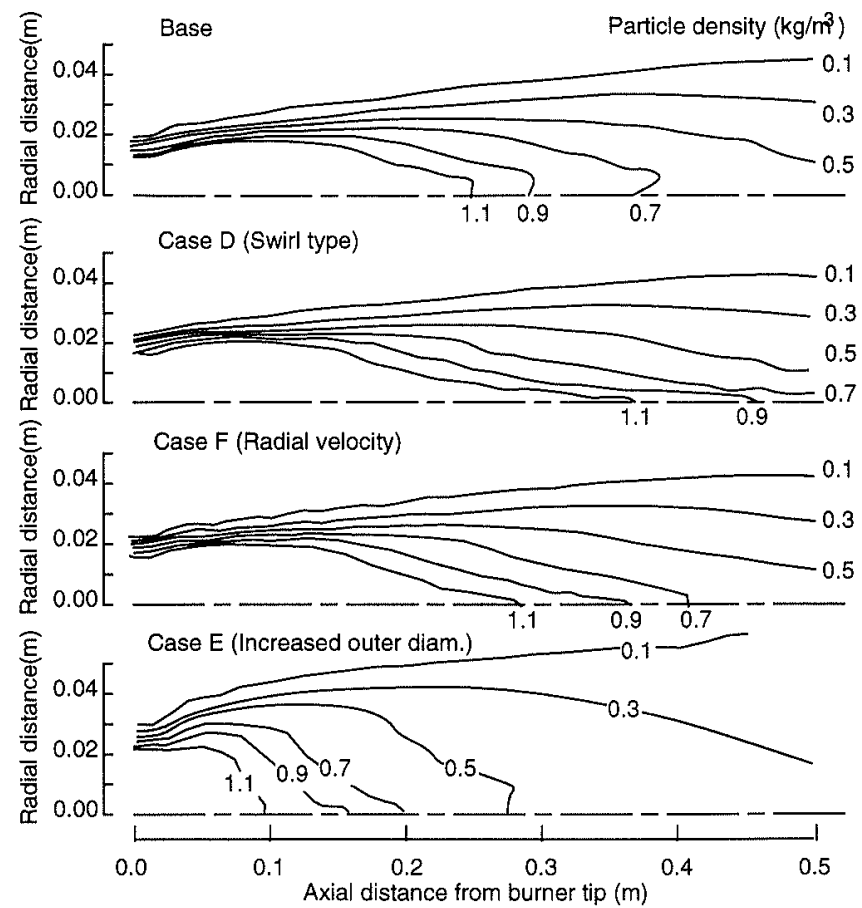

Fig. 18. Contours of the particle mass density at the region close to the burner.

Case D: Swirl imposed to the primary air and coal.

Case $\mathrm{E}$ : Increase in outer diameter.

Case F : Initial radial velocity of gas and particles.

\subsection{Effect of PC Diameter}

The influences of particle diameter of $\mathrm{PC}$ on the burnout were examined with the mathematical model. Calculations were carried out for the injection of the 


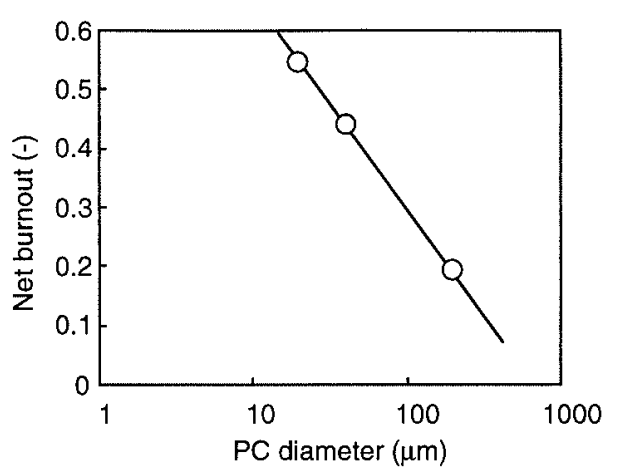

Fig. 19. Effect of mean diameter of pulverised coal on burnout.

average particle diameter ranged from 20 to $200 \mu \mathrm{m}$ with an injection rate of $200 \mathrm{~kg} \mathrm{tHM}^{-1}$. The result clearly shows a linear decrease in the burnout as an increase in the particle diameter as shown in Fig. 19. All combustion processes such as devolatilisation, volatile combustion and char combustion are shifted downstream by the increased particle size. Favourable factors for the large particles on the PC combustion rely on the strong interaction with coke particles and the resultant longer residence time in the raceway. These factors are cancelled out by the delayed devolatilisation and char combustion rates.

Granular coal injection has been developed by the British Steel Corp. and some other European steel works. ${ }^{23)}$ The decrease in the burnout for the large PC particles does not support the operational experiences in the British Steel Corp. There may be two possible explanations for the discrepancies: the fragmentation of large particles by the rapid heating and recycling of the PC particles deposited on the coke surface.

\section{Conclusions}

The total mathematical model of PC combustion in the tuyere and raceway was developed by introducing the turbulence model and stochastic calculation of particle trajectories in a packed bed along with all other pertinent phenomena.

Validation work against measurements in two industrial blast furnaces indicates that the model works satisfactorily for simulations with and without PC in- jection. Various measures for burnout improvements have been explored under an injection rate of $200 \mathrm{~kg}$ $\mathrm{tHM}^{-1}$. Notable improvements are observed by oxygen enrichment to the secondary air and increasing an outer diameter of the injection burner.

\section{REFERENCES}

1) S. Wakuri, M. Baba and K. Kanamori: Ironmaking Steelmaking, 10 (1983), 98.

2) K. Kakiuchi, S. Matsunaga, A. Sakamoto, H. Matsuoka, H. Ueno and K. Yamaguchi: CAMP-ISIJ, 7 (1994), 126.

3) M. Atsushi, N. Nakaya, S. Kitano, Y. Yamagata, K. Shibata, T Goto, R. Ono and T. Yabata: CAMP-ISIJ, 8 (1995), 321.

4) K. Mori, N. Takagaki, H. Inoue, H. Mitsufuji, S. Kishimoto and A. Sakai: CAMP-ISIJ, 8 (1995), 319.

5) Tekko-Kai-Ho, (1992), November, No. 1577, 4.

6) T. Suzuki, L. D. Smoot, T. H. Fletcher and P. J. Smith: Combustion Science and Technology, 45 (1986), 167.

7) A. S. Jamaluddin, T. F. Wall and J. S. Truelove: Ironmaking Steelmaking, 13 (1986), 91.

8) A. S. Jamaluddin: A thesis submitted for the degree of Doctor of Philosophy, The University of Newcastle, (1985).

9) J. C. He, M. Kuwabara and I. Muchi: Tetsu-to-Hagané, 72 (1986), 1847.

10) M. Hatano, K. Kurita and T. Tanaka: Int. Blast Furnace Hearth and Raceway Symp., Newcastle, Australia, Symposium Series, Australasian Inst. of Mining and Metallurgy, 26 (1981), 4-1.

11) H. Nogami, T. Miura and T. Furukawa: Tetsu-to-Hagané, 78 (1992), 1222.

12) K. Takeda and F. C. Lockwood: Tetsu-to-Hagané, 82(1996), 486.

13) K. Takeda and F. C. Lockwood: Tetsu-to-Hagané, 82 (1996), 492.

14) T. Inatani, K. Okabe, T. Nishiyama, Y. Serizawa, H. Takahash and M. Saino: Tetsu-to-Hagané, 62 (1976), 514.

15) S. M. A. Rizvi: Thesis submitted for the degree of Doctor of Philosophy of the University of London, (1985).

16) F. C. Lockwood, K. Takeda and M. Yehia: 10th IFRF Members Conf., (1992), the Netherland.

17) B. F. Magnussen and B. H. Hjertager: 16th Symp. (Int.) on Combustion, (1976), 719

18) J. F. Elliott, R. A. Buchanan and J. B. Wagstaff: J. Met, Trans. AIME, (1952), 709.

19) K. Nozawa, T. Kamijo and M. Shimizu: Tetsu-to-Hagané, 81 (1995), 882.

20) M. Nakamura, T. Sugiyama, T. Uno, Y. Hara and S. Kondo: Tetsu-to-Hagané, 63 (1977), 28.

21) D. A. Campbell, G. Flierman, G. Malgarinio and R. B. Smith: Proc. of Second European Ironmaking Cong., Glasgow, (1991), 263.

22) Y. Ohno, T. Furukawa and M. Matsuura: CAMP-ISIJ, 4 (1991), 80.

23) K. H. Peters, E. Beppler, B. Korthas and M. Peters: Proc. of Second European Ironmaking Cong., Glasgow, (1991), 247. 